\title{
Política Distributiva na Federação: Estratégias Eleitorais, Barganhas Legislativas e Coalizões de Governo*
}

\author{
Marta Arretche \\ Jonathan Rodden
}

$\mathrm{M}$ uitos cientistas políticos concordariam com a famosa afirmação de Harold Lasswell (1936) de que o estudo da política freqüentemente se resume a questões de distribuição: quem ganha o que, quando e por que. Quando o governo usa sua autoridade para taxar, gastar e regular, quem são os principais beneficiários? Um objeto empírico promissor para a análise da questão levantada por Lasswell está no campo das transferências fiscais, mais especificamente na análise do impacto distributivo do gasto público sobre unidades geográficas.

Esse tipo de análise é particularmente relevante para o estudo do federalismo brasileiro, descrito como historicamente soldado por coalizões cuidadosamente construídas entre e com as elites regionais (Camargo, 1993), alianças estas nas quais o gasto público ocupa um lugar

\footnotetext{
* Este artigo é uma versão modificada do trabalho Legislative Bargaining and Distributive Politics in Brazil: An Empirical Approach, apresentado no Encontro Anual da American Political Science Association - APSA, em Filadélfia, em agosto de 2003. Os autores agradecem os comentários de Argelina Figueiredo, Maria Hermínia Tavares de Almeida, Fernando Limongi, David Samuels, Eduardo Marques, Celina Souza e Richard Locke. Para a produção deste artigo, agradecem ainda o apoio institucional da Fundação de Amparo à Pesquisa do Estado de São Paulo - FAPESP, sob a forma de bolsa de pós-doutoramento para Marta Arretche no Massachusetts Institute of Technology - MIT e o suporte financeiro do MIT à viagem de Jonathan Rodden ao Brasil.
}

DADOS - Revista de Ciências Sociais, Rio de Janeiro, Vol. 47, nº3, 2004, pp. 549 a 576. 
central (Affonso, 1995). A percepção dominante entre os cientistas políticos é a de que as instituições políticas desenhadas a partir da Constituição de 1988 não alteraram essas características da federação brasileira (Almeida, 2001). A visão comum é a de que elites poderosamente instaladas nos estados controlam recursos que lhes permitem cobrar um alto preço para que quaisquer mudanças no status quo sejam realizadas.

O objetivo deste artigo é trazer uma contribuição ao debate sobre "como se governa o Brasil" (Palermo, 2000), testando empiricamente hipóteses da literatura sobre o funcionamento do federalismo brasileiro. O exame da distribuição regional de recursos fiscais permitirá testar hipóteses sobre estratégias eleitorais e legislativas dos governantes brasileiros.

No campo das estratégias eleitorais, o artigo procura identificar os estados para os quais os líderes políticos preferencialmente destinam recursos. Uma destas estratégias, avessa a riscos, seria a de investir nas regiões onde os líderes partidários sabem que seu apoio já é forte (Cox e McCubbins, 1986). Uma estratégia alternativa consistiria em eleger como distritos eleitorais preferenciais aqueles nos quais um número expressivo de eleitores indecisos poderia ser conquistado através de gastos localizados (Dixit e Londregan, 1996; Lindbeck e Weibull, 1987).

Um limite dessas interpretações é seu suposto de que o partido do governo tem inteira autoridade sobre a agenda política. Conflitos entre os membros de uma coalizão de governo ou entre o Executivo e o Legislativo são ignorados. Em primeiro lugar, o próprio processo orçamentário pode constranger a autonomia do Executivo, ao conferir poder de veto ou emendas a comissões, líderes partidários ou outros atores. Em segundo lugar, em vez de usar sua autoridade sobre o processo orçamentário para conquistar eleitores ou influenciar futuras eleições, o partido do governo pode ter preocupações mais imediatas, tais como sobreviver ao voto de confiança ou aprovar uma dada legislação. Em outras palavras, quando a disciplina partidária é relativamente fraca ou o governo se apóia sobre uma coalizão, a necessidade de obter votos parlamentares pode ser superior ao interesse por premiar eleitores cativos ou conquistar os indecisos. 
Comparativamente, os presidentes brasileiros têm grande poder sobre o processo de elaboração e execução do orçamento. A possibilidade do uso estratégico de recursos fiscais para premiar antigos eleitores ou conquistar novos é, assim, uma hipótese plausível de ser examinada, particularmente com relação a Fernando Henrique Cardoso, o primeiro presidente brasileiro a concorrer à reeleição. Por outro lado, os presidentes brasileiros enfrentam a tarefa de obter aprovação legislativa em um parlamento com oito partidos efetivos, em que o partido do presidente usualmente controla menos de $20 \%$ das cadeiras, com a dificuldade adicional de que as emendas constitucionais têm sido um componente central na agenda dos governos, requerendo maiorias de dois terços para aprovação.

Assim, as barganhas legislativas são um segundo componente central deste artigo. A idéia de que os presidentes brasileiros trocam gastos localizados por apoio legislativo não é nova. Entretanto, este trabalho contraria a visão de um "mercado caótico" de votos legislativos em favor de uma visão de que há acordos de longo prazo e relativamente estáveis entre o presidente e sua coalizão de sustentação legislativa (Figueiredo e Limongi, 1999). Apoiado nos trabalhos de Samuels (2000) e Abrucio (1998), este trabalho testa ainda o papel dos governadores de Estado nas barganhas legislativas e na política de distribuição de recursos fiscais.

A primeira seção revisa abordagens teóricas sobre a distribuição espacial de recursos e explora implicações empíricas para o caso brasileiro, dando especial atenção às estratégias eleitorais e legislativas dos líderes partidários. A segunda, apresenta as hipóteses de trabalho, bem como a metodologia empregada para a análise empírica. A terceira apresenta os resultados do trabalho.

\section{TEORIAS DE REDISTRIBUIÇÃO APLICADAS AO BRASIL}

As teorias sobre a distribuição espacial de recursos fiscais evoluíram lentamente a partir da tradição da Economia do Bem-Estar. Aliteratura tradicional sobre federalismo fiscal concebia o governo central como um ditador benevolente, que opera transferências de modo a internalizar externalidades entre as jurisdições (Musgrave, 1959; Oates, 1972). Um outro enfoque de análise sobre o problema da redistribuição nos Estados modernos é ver o governo central não como um ator individual benevolente, mas como uma arena pela qual preferên- 
cias são transformadas em políticas. Um exemplo clássico dessa abordagem é o trabalho de Meltzer e Richard (1981), os quais afirmam que os pobres são capazes de extrair transferências dos ricos por meio do processo democrático. Uma outra abordagem da redistribuição considera que esta é o resultado da decisão de indivíduos ricos e altruístas que preferem ajudar os pobres (Becker, 1974; Coate, 1995). De acordo com esta visão, seria de se esperar que, dada a elevada desigualdade na distribuição da renda entre as regiões brasileiras, a distribuição de recursos fiscais operasse em favor das regiões relativamente mais pobres.

Nessas teorias, contudo, a política e as instituições estão completamente ausentes. Nenhum observador atento da vida política e da política fiscal brasileiras concordaria com a afirmativa de que o governo central pode ser descrito como um déspota benevolente ou um conjunto vazio através do qual o eleitor médio expressa suas preferências. Alguns formuladores de políticas podem de fato ser motivados pelo desejo de internalizar externalidades ou mesmo por altruísticas preocupações com os mais pobres. Ainda assim, esse ator será constrangido pelo contexto político em que está obrigado a atuar. Para viabilizar sua agenda política, terá de reunir maiorias legislativas, manter-se no cargo e sobreviver politicamente.

Assim, esse artigo adota a suposição de que o interesse por conquistar cargos, permanecer no poder, controlar o executivo ou integrar coalizões legislativas majoritárias é um objetivo central dos atores políticos. De acordo com esta visão, a distribuição de transferências intergovernamentais pode ser uma ferramenta extremamente valiosa não apenas para atingir objetivos de política, mas também para premiar antigos e persuadir novos colaboradores, bem como construir e manter coalizões majoritárias no parlamento. Levando em conta a influência das instituições políticas sobre o processo decisório, este artigo assume que dois países com idênticas estruturas de distribuição da renda podem apresentar padrões inteiramente distintos de redistribuição fiscal se as regras que estruturam os processos legislativo e eleitoral forem diferentes.

\section{O Processo de Distribuição de Recursos: Orçamento e Fundo de Garantia por Tempo de Serviço - FGTS}

Para a análise política da distribuição de recursos fiscais, é importante identificar os principais atores e seus constrangimentos institucio- 
nais. O mais importante ator no processo orçamentário brasileiro é o presidente. Comparado com outros sistemas presidencialistas, o sistema brasileiro confere grande autoridade legislativa e orçamentária ao presidente (Figueiredo e Limongi, 1999), mas o papel dos líderes partidários no processo orçamentário também é central (idem; Souza, 2003).

O processo inicia-se com a apresentação da proposta orçamentária ao Congresso, que passa então a ser examinada pela Comissão Mista do Orçamento - CMO, composta por membros do Senado e da Câmara dos Deputados ${ }^{1}$. A composição partidária da $\mathrm{CMO}$ e de suas subcomissões é proporcional à distribuição partidária das cadeiras nas duas Casas. Os líderes partidários desempenham um importante papel nesse processo, devido à sua autoridade para indicar os membros de seus próprios partidos que integrarão a Comissão, as subcomissões e as relatorias. O cargo mais importante é o de relator geral - que é sempre um parlamentar-chave na coalizão de apoio ao presidente-, que desempenha o papel de negociar emendas ao orçamento entre os líderes partidários e o presidente.

Os estudos sobre as políticas de distribuição de recursos governamentais no Brasil concentram-se no processo de proposição de emendas ao orçamento. As emendas podem ser apresentadas por parlamentares individuais, bancadas estaduais, bancadas regionais ou comissões. A visão clássica sobre o processo de barganha legislativa no Brasil destaca a apresentação de emendas ao orçamento como uma estratégia de parlamentares individuais para conseguir projetos para seus distritos eleitorais (Ames, 1995). Na verdade, mudanças nas regras de proposição das emendas a partir de 1995 criaram fortes incentivos para que estas sejam apresentadas coletivamente, particularmente pelas bancadas estaduais em detrimento das estratégias individualistas (Figueiredo e Limongi, 2002; Souza, 2003)². Além desses incentivos, o sucesso de um parlamentar na aprovação de emendas individuais depende de negociações com os líderes partidários e os relatores para obter aprovação nas comissões.

A apresentação de emendas é apenas o início do processo. Mesmo depois de aprovadas, o presidente tem inteira autoridade sobre sua execução. No primeiro governo Fernando Henrique, pouco mais da metade das emendas aprovadas foi executada (Figueiredo e Limongi, 2002). O presidente tem ainda autoridade sobre o timing de liberação 
dos recursos, isto é, a data em que as emendas aprovadas serão efetivamente executadas. Finalmente, embora raramente empregado, o presidente tem poder de veto sobre as emendas aprovadas (Souza, 2003). Em suma, o processo orçamentário começa e termina sob a autoridade do presidente; os líderes partidários têm grande controle sobre a indicação de cargos estratégicos na formulação do orçamento, e estratégias individuais de inserção de emendas de caráter particularista têm tido seu espaço crescentemente reduzido.

O Executivo federal também tem grande autoridade sobre a distribuição dos empréstimos do FGTS, recurso extra-orçamentário cuja política de distribuição também será examinada neste artigo. O processo inicia-se com a avaliação pela Caixa Econômica Federal - CEF da capacidade de endividamento de cada instituição que queira solicitar um empréstimo. Nessa etapa, a CEF tem poder de veto sobre a aprovação do projeto. Em seguida, instâncias colegiadas estaduais têm autoridade para definir as áreas prioritárias de alocação dos empréstimos dentro de cada unidade federativa, com base em um orçamento anual. Os critérios de alocação de recursos de tais instâncias estaduais são definidos pelo ministério encarregado da gestão da política habitacional e urbana e pelo Conselho Curador do FGTS, órgão federal em que governos estaduais e municipais não têm representação. $\mathrm{O}$ ministério tem ainda autoridade para avaliar a qualidade técnica do projeto aprovado, acelerando ou retardando o processo de liberação dos recursos. ACEF tem ainda grande autoridade sobre o timing da liberação dos recursos. Finalmente, caso a arrecadação do FGTS não se comporte de acordo com o previsto quando da elaboração dos orçamentos estaduais, a liberação de recursos aprovados pode ser postergada para o ano seguinte.

\section{Conquistando votos para as eleições presidenciais}

A descrição acima sugere que há espaço na formulação e execução do orçamento e na distribuição dos recursos do FGTS para que os presidentes brasileiros usem estes recursos para conquistar eleitores.

Duas interpretações da literatura podem ser úteis para analisar esse fenômeno. Cox e McCubbins (1986) sugerem que governantes avessos a riscos tenderão a investir nas regiões das quais receberam apoio nas eleições mais recentes. Uma explicação alternativa sustenta que esta estratégia desperdiçaria recursos valiosos em distritos eleitorais 
já cativos. Uma estratégia mais eficiente seria destinar recursos para aqueles distritos em que os resultados das próximas eleições seriam mais incertos, onde os eleitores estejam eventualmente divididos. Mais explicitamente, Dixit e Londregan (1996) argumentam que o partido que controla o governo central escolheria destinar recursos para os distritos em que um grupo relativamente grande de eleitores indecisos e com frágil identidade ideológica seria mobilizado eleitoralmente por meio de gastos localizados.

O mais óbvio problema para o emprego dessas teorias no caso brasileiro reside no fato de que até 1998 os presidentes não podiam concorrer à reeleição. Entretanto, é plausível supor que os presidentes no poder tenham tentado favorecer a eleição dos candidatos de seus próprios partidos. Uma segunda cautela deve levar em conta que estas teorias assumem explícita ou implicitamente regras eleitorais em que o "vencedor leva tudo". Por exemplo, nas eleições presidenciais norte-americanas, faz sentido "mirar um distrito-chave", como é a Flórida, para a composição do colégio eleitoral (Strömberg, 2001). No caso do Brasil, os votos de todos os eleitores são igualmente válidos. Nesse caso, pode não fazer tanto sentido concentrar recursos em um estado-pivô, mas favorecer o gasto em estados ou regiões com maior número de eleitores.

A despeito dessas hesitações, essas duas hipóteses serão testadas empiricamente neste trabalho.

\section{Conquistando votos no Parlamento}

Os presidentes brasileiros enfrentam uma complexa tarefa para construir suas coalizões de sustentação parlamentar nas duas Câmaras. O sistema partidário brasileiro é altamente fragmentado (Kinzo, 1993; Nicolau, 1996). As coalizões eleitorais são freqüentemente diferentes das coalizões de governo. As regras eleitorais não criam incentivos para que os parlamentares dêem suporte à agenda legislativa do presidente, porque seus mandatos não são mutuamente dependentes. Os parlamentares têm fortes incentivos para conseguir que os gastos governamentais se dirijam para as suas regiões de origem.

De acordo com a literatura, a tarefa seria dificultada pela fragmentação política derivada do federalismo. Os governadores de estado são importantes jogadores na construção das coalizões eleitorais. Estu- 
dos empíricos sugerem que os candidatos a postos eletivos no nível federal dependem do apoio dos governadores, que têm um papel relevante na montagem das listas eleitorais (Samuels, 2000). Portanto, os governadores teriam mecanismos de controle sobre a sobrevivência eleitoral dos parlamentares - particularmente no Senado -, dificultando os esforços dos presidentes para construir coalizões de sustentação parlamentar (Mainwaring, 1997; Abrucio, 1998). A própria unidade do Executivo federal seria ameaçada pela lealdade dos ministros às suas regiões de origem em detrimento da lealdade à agenda legislativa do presidente (Ames, 2001).

Essas dificuldades para a construção de coalizões de governo seriam as responsáveis por diversos dos problemas brasileiros, que vão do desequilíbrio fiscal, déficit público, inflação (Dillinger e Webb, 1999) à estagnação econômica (Lopes, 1996), passando pela paralisia decisória (Ames, 2001). Entretanto, os presidentes brasileiros, de Sarney a Lula, têm governado sob o "presidencialismo de coalizão" (Figueiredo e Limongi, 1999) e não encontraram barreiras intransponíveis ao cumprimento de sua agenda, mesmo em questões que contrariam os interesses imediatos de governadores de Estado, aí incluído o grau mais exigente de sucesso parlamentar que é a aprovação de emendas constitucionais (Arretche, 2002; Melo, 2002).

Os presidentes brasileiros têm de fato grande autoridade sobre uma série de programas associados a transferências fiscais e fortes incentivos para trocar gastos federais por votos legislativos. Trata-se de saber como eles têm construído suas coalizões de sustentação parlamentar.

\section{Acordos aleatórios caso a caso}

A interpretação que sugere que as maiorias legislativas são construídas a cada votação parlamentar considera, de um lado, um presidente que deseja usar um conjunto limitado de recursos para comprar votos em uma variedade de tramitações legislativas durante seu mandato e, de outro lado, parlamentares que desejam se reeleger distribuindo benefícios a seus distritos eleitorais. Pode ser racional para um presidente construir diferentes coalizões majoritárias para a aprovação de diferentes projetos de lei. Nessa situação, cada votação engendraria um mercado de votos parlamentares e, portanto, as relações do presidente com o parlamento pautariam-se por acordos aleatórios. Em 
face da tarefa de alocar limitados recursos a regiões específicas, o presidente poderia identificar as preferências e os pontos fracos de cada parlamentar com relação a cada projeto de lei e "mirar" aqueles parlamentares cuja indiferença em relação ao resultado da votação em questão os tornaria dispostos a serem comprados.

Se preferências e pontos fracos variam de acordo com o assunto em pauta, os presidentes fariam melhor uso de seus recursos construindo as coalizões menos caras para cada projeto sob tramitação legislativa. Para construir a coalizão menos cara neste método do caso a caso, o presidente deveria "comprar" o número mínimo de parlamentares necessário para obter vitória nas votações. A compra de parlamentares em número superior ao necessário à aprovação da lei em questão significaria desperdiçar preciosos recursos que precisariam ser preservados para batalhas futuras.

Todos os distritos eleitorais poderiam vir a ser beneficiados caso tivessem o mesmo número de votos, isto é, igual poder de barganha no mercado de compra de votos parlamentares. Entretanto, as bancadas estaduais podem ser de tamanho diferente, de acordo com as leis eleitorais que definem as regras de distribuição das cadeiras por estados. No caso brasileiro, os estados menores são sobre-representados nas duas Casas federais. Na estratégia de poupar limitados recursos de uso discricionário, o presidente buscaria os votos parlamentares que podem ser comprados por mais baixo preço. Assim, os representantes dos estados menores poderiam tornar-se particularmente atraentes no mercado de votos parlamentares, dado que seus votos seriam menos caros. Se isto for verdade, poder-se-ia esperar que os estados menores, sobre-representados, acabariam por obter um valor per capita maior na distribuição das transferências fiscais.

\section{Contratos de longo prazo}

A estratégia de construir maiorias legislativas a cada votação parlamentar pode ter custos proibitivos, sobretudo os que envolvem reunir informação e organizar diferentes grupos parlamentares para a compra de votos (Weingast e Marshall, 1988). Além disto, a não-simultaneidade das ações pode dificultar significativamente a manutenção dos compromissos. Os recursos não podem ser liberados no mesmo momento em que ocorrem as votações; assim, o primeiro a 
cumprir sua parte no acordo pode temer que o segundo não venha a honrar o compromisso assumido ${ }^{3}$.

Esses problemas engendrariam incentivos para que sejam criadas estruturas de negociação que vão além do tratamento caso a caso. Nos EUA, por exemplo, o sistema de comissões desempenha esse papel. No Brasil, essa estrutura pode ser a coalizão legislativa. Ao invés de firmar acordos aleatoriamente, o presidente pode estabelecer compromissos de longo prazo no início de seu mandato, premiando os membros de sua coalizão de sustentação parlamentar com um fluxo regular de recursos.

Entretanto, essa estratégia pode apresentar problemas. Em primeiro lugar, em uma legislatura grande, pode ser difícil para o presidente supervisionar diretamente um grande número de desembolsos. Além disso, a construção de uma coalizão parlamentar não elimina o problema da não-simultaneidade. Para resolver este problema, o presidente pode delegar a tarefa de distribuição de recursos aos seus ministros, oferecendo-lhes autonomia. Os ministros agiriam, assim, como intermediários na troca de votos por transferências (Ames, 2001). O presidente distribui quotas de recursos entre seus ministros, na expectativa de que estes as utilizem nas negociações com os líderes partidários e parlamentares de modo a assegurar uma oferta estável de votos ${ }^{4}$.

Esse arranjo não seria preferível somente para o presidente, mas também para os parlamentares os quais estariam, acima de tudo, garantindo recursos para seus próprios distritos. A capacidade de firmar compromissos de longo prazo que garantam recursos para suas bases eleitorais pode ser vista como superior a um imprevisível mercado aleatório de votos no qual tais recursos não estariam garantidos. De acordo com essa linha de interpretação, os partidos têm incentivos para permanecer na coalizão de governo porque seus membros são premiados com recursos políticos sobre os quais o presidente tem grande autoridade, assim como parlamentares têm incentivos para migrar para os partidos da coalizão, caso as regras partidárias o permitam $^{5}$.

Alternativamente, ou talvez adicionalmente aos ministros e líderes partidários, os presidentes podem usar os governadores como intermediários. Dado que estes jogam um importante papel na sobrevi- 
vência eleitoral dos parlamentares, podem ter instrumentos que lhes permitam influenciar o comportamento parlamentar, tornando-se, assim, úteis ao presidente (Samuels, 2000). O presidente pode delegar recursos federais aos governadores de sua própria coalizão, e estes por sua vez distribuem esses recursos aos parlamentares cujos votos são necessários.

As análises mais recentes sugerem um conflito entre a interpretação centrada no poder dos líderes partidários (Figueiredo e Limongi, 1999) e a visão centrada na supremacia dos governadores (Samuels, 2000). Entretanto, Carey e Reinhardt (2003) afirmam que estas não são mutuamente exclusivas, e que de fato governadores tendem a competir com os líderes partidários como intermediários entre o presidente e os parlamentares, bem como influir nas decisões legislativas. Uma contribuição do trabalho em questão consiste em testar empiricamente essas duas possibilidades.

\section{Hipóteses}

Diversas teorias do federalismo fiscal prevêem que as transferências intergovernamentais tenderão no longo prazo a beneficiar os estados mais pobres. Uma outra perspectiva sugere que os presidentes podem usar as transferências intergovernamentais para conquistar eleitores e vencer as eleições, ou conquistar parlamentares e construir coalizões legislativas vitoriosas. A estratégia de conquistar eleitores pode tanto "mirar" regiões onde o partido do presidente já é muito forte quanto regiões em que o presidente não recebeu a maioria dos votos na última eleição, mas que contam com um grande contingente de eleitores.

A estratégia de conquista de votos parlamentares pode ser tanto de firmar compromissos caso a caso ou de longo prazo. Na primeira estratégia, todas as coalizões são igualmente prováveis de serem formadas. Disciplina partidária, ideologia ou vínculos regionais não são importantes para que os acordos sejam firmados. Se esta visão estiver correta, partidos ou coalizões não terão um impacto importante na distribuição das transferências, mas estados pequenos, sobre-representados nas câmaras federais tenderão a receber maiores valores per capita. Se a interpretação centrada nos compromissos de longo prazo estiver correta, pode-se esperar que distritos controlados pelos partidos ou pelos governadores pertencentes à coalizão do pre- 
sidente receberão montantes per capita mais elevados. Neste caso, o objetivo não seria de comprar a coalizão vitoriosa mais barata, mas de conservar uma coalizão de governo.

\section{Análise Empírica}

Esta seção tenta estimar a influência das políticas eleitoral e legislativa na distribuição de transferências intergovernamentais. Do melhor de nosso conhecimento, este é o primeiro esforço analítico nesta direção. Ames (2001) analisou as propostas de emendas ao orçamento, embora freqüentemente menos da metade destas sejam executadas. Figueiredo e Limongi (2002) e Pereira e Mueller (2002) examinaram os itens executados do orçamento de investimentos de Fernando Henrique Cardoso e mostraram que os parlamentares da coalizão do presidente têm maior probabilidade de ter suas emendas aprovadas e executadas. O foco analítico desses estudos, contudo, era o processo orçamentário e os desembolsos analisados que representam menos que 5\% do orçamento total. Pensamos que examinar as transferências intergovernamentais efetivamente executadas é uma forma mais adequada de analisar as implicações da política sobre a distribuição espacial de recursos em uma federação.

Dado que todos os argumentos teóricos acima supõem uma razoável dose de autoridade do presidente, é necessário examinar transferências cuja natureza permita testar o uso dessa autoridade. Os efeitos políticos que pretendemos analisar são mais discerníveis com transferências discricionárias do que automáticas ou constitucionais ${ }^{6}$. É assim útil distinguir as transferências totais (incluindo as constitucionais) daquelas sobre cuja distribuição o Executivo federal tem algum grau de discricionariedade. Assim, coletamos informações anualizadas sobre três tipos de fluxo de transferências federais: empréstimos do FGTS (de 1995 a 1998) ; transferências voluntárias para estados e municípios (de 1996 a 2000) ${ }^{8}$ e todas as transferências (distinguindo as constitucionais das não constitucionais (1991-2000) .

Para facilitar as comparações, os valores absolutos foram corrigidos pela população e deflacionados; todos os cálculos foram feitos em Reais per capita de 1995, tomando os estados como unidade de análise ${ }^{10}$.

Diversas variáveis foram criadas para avaliar a possibilidade de uso estratégico das transferências discricionárias pelo presidente. Para 
testar a hipótese de que as transferências foram usadas com objetivos eleitorais, simplesmente empregamos uma variável dummy para os anos eleitorais e, além disso, calculamos o número total de votos recebidos pelo presidente eleito em cada estado na eleição mais recente. Caso o presidente tenha premiado o apoio recebido, deveríamos encontrar maiores montantes per capita de transferências para aqueles estados em que este obteve maior votação. Para testar a hipótese contrária, de que a estratégia dos presidentes tenha sido de "conquistar os estados divididos", calculamos a diferença entre os dois candidatos mais votados em cada estado na última eleição presidencial, esperando encontrar um coeficiente negativo nas correlações ${ }^{11}$. Em terceiro lugar, para testar a hipótese de que os estados mais favorecidos são aqueles que contam com maior número de eleitores, calculamos a participação efetiva nas eleições presidenciais mais recentes.

Para testar a hipótese de que os estados menores - sobre-representados - são os mais beneficiados pelas transferências federais, foi calculado o número de cadeiras por milhão de habitantes de cada estado, na Câmara dos Deputados e no Senado. Como estas são altamente correlacionadas, usamos a média das duas Casas, em vez de colocá-las separadamente nas regressões. A média das duas Câmaras varia entre cerca de 1 para São Paulo e 35 para Roraima.

Para testar a hipótese de que o pertencimento ao partido da coalizão de sustentação do presidente favorece o acesso às transferências federais, calculamos o número de deputados em cada estado que pertencem à coalizão de sustentação do presidente em relação ao total de cadeiras legislativas, separadamente para a Câmara dos Deputados e o Senado. Novamente, dado que os poderes legislativos das duas Casas são bastante semelhantes no processo legislativo, calculamos a média das duas Casas. Essas medidas nos permitiram medir a importância de cada estado na coalizão de sustentação parlamentar do presidente. Essas variam entre cerca de 0,001 para Goiás no início dos anos 90 e cerca de 0,05 para Minas Gerais no primeiro governo Fernando Henrique.

É possível que os efeitos da sobre-representação e pertencimento à coalizão do presidente sejam interativos antes que aditivos. Isto é, os estados menores podem ser parceiros mais atraentes quando o presidente forma sua coalizão de governo. O valor de ter um número de cadeiras legislativas per capita pode ser fortalecido quando estas cadei- 
ras são parte da coalizão de governo. Assim, incluímos um termo de interação dessas duas variáveis.

Para testar a hipótese de que os governadores da coalizão do presidente operam como intermediários entre este e as bancadas parlamentares dos estados, simplesmente construímos uma variável dummy atribuindo valor um se o governador era membro da coalizão de governo e valor zero no caso de não-pertencimento, bem como uma variável dummy separada para os governadores que pertencem ao mesmo partido do presidente. Se essa hipótese se confirmar, os estados governados por aliados do presidente devem receber mais recursos per capita que os demais.

Finalmente, consideramos necessário testar as proposições das teorias que prevêem resultados redistributivos em direção às regiões mais pobres. Seja por motivos altruísticos, seja pelo poder eleitoral dos pobres, as transferências são em grande parte apresentadas como tendo entre seus objetivos a finalidade de redistribuir recursos para as regiões mais necessitadas. A mais importante variável de controle é o log do Produto Interno Bruto - PIB per capita estadual. O coeficiente deve ser negativo se o governo central empregar as transferências para redistribuir renda às regiões mais pobres. Incluímos ainda uma bateria de variáveis demográficas de controle, tais como pobreza, analfabetismo, urbanização, bem como o Índice de Desenvolvimento Humano - IDH estadual. Esses dados, entretanto, não variam significativamente ao longo do tempo; assim, foram deixados de fora dos modelos de séries temporais cross-section. Finalmente, incluímos a população dos estados e uma variável dummy para os anos de eleições presidenciais $^{12}$.

\section{Resultados}

\section{Transferências constitucionais e não constitucionais}

A Tabela 1 apresenta os resultados para o total das transferências: constitucionais e não constitucionais. Nos Modelos 1 e 2, a variável dependente é o total de transferências per capita (incluindo as constitucionais); nos Modelos 3 e 4, esta é o total de transferências sobre as quais há algum grau de discricionariedade do Executivo federal (isto é, total das transferências - transferências constitucionais). Os Mode- 
Política Distributiva na Federação: Estratégias Eleitorais, Barganha...

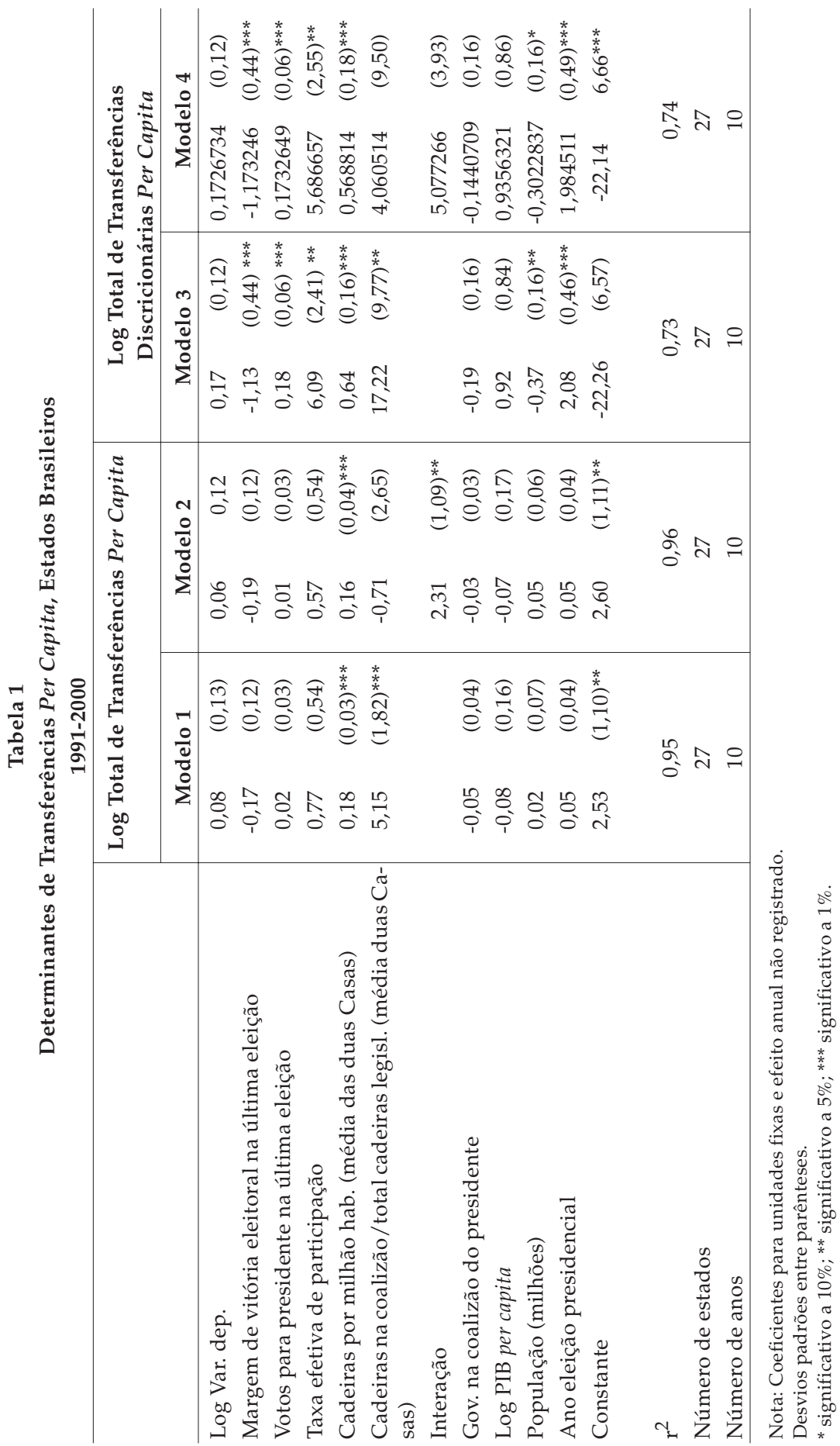


los 1 e 3 não incluem o termo de interação, ao passo que os modelos 2 e 4 o incluem.

O primeiro grupo de variáveis independentes examina as teorias rivais de conquista de eleitores em eleições presidenciais. Esses coeficientes não são significativamente diferentes de "zero" nos dois primeiros modelos, mas os resultados dos modelos 3 e 4 são interessantes. A diferença dos votos recebidos pelos dois candidatos mais votados tem um efeito negativo sobre as transferências não constitucionais. Mantidas todas as médias das variáveis, cada desvio padrão a menos na margem de vitória está associado a um ganho per capita de $\mathrm{R} \$ 7$ nas transferências não constitucionais. O coeficiente seguinte - de vitória do presidente na última eleição - sugere que, outros valores mantidos iguais, os estados que deram mais votos ao presidente na eleição mais recente receberam maiores montantes de transferências não constitucionais per capita. Cada desvio padrão a mais em votos para o presidente está associado a um acréscimo de $\mathrm{R} \$ 17$ nas transferências não constitucionais.

Do mesmo modo, estados com maiores taxas de participação eleitoral (isto é, com maior número absoluto de eleitores) receberam maiores transferências não constitucionais per capita. Entretanto, um plot residual revela que esse resultado é fortemente influenciado por Tocantins. Quando este estado é retirado, o coeficiente não é mais significativamente distinto de "zero".

O fato de que os coeficientes são significativos tanto para a margem de vitória eleitoral quanto para a vitória do presidente requer explicações adicionais. Assim, testamos a influência de outliers e examinamos a estabilidade dos coeficientes ao longo do tempo. Descobrimos que ambos os coeficientes são puxados pelo período de Fernando Henrique Cardoso, não sendo significativos até 1995. Este resultado indicaria que a motivação da reeleição - plausível somente para Fernando Henrique - explicaria a redistribuição estratégica de recursos discricionários.

Entretanto, permanece o problema de que os resultados favorecem ambas as teorias - de favorecimento aos distritos cativos e de conquista por distritos indecisos. A inserção de um termo de interação (margem $\mathrm{x}$ votos para o presidente) no Modelo 4 ajuda a resolver a questão. A interação e seus componentes são significativos conjunta- 
mente. O coeficiente condicional para voto no presidente - isto é, estado em que o presidente eleito foi o mais votado na última eleição - é significativo e eleva-se lentamente com a margem de vitória - isto é, a distância em relação ao segundo candidato mais votado. Entretanto, o coeficiente para margem de vitória só é negativo nos estados em que o presidente obteve menos do que um milhão de votos; e mesmo nestes, o coeficiente não é estatisticamente significativo para toda a amostra. Quando o presidente recebeu mais do que 1 milhão de votos, o coeficiente condicional para margem de vitória torna-se na verdade positivo; e é significativo quando o número de votos passa de 2 milhões ${ }^{13}$. Assim para os estados maiores, o efeito da margem de vitória é positivo; e o presidente ganhou as eleições nestes estados em $90 \%$ dos casos (a maior margem de vitória foi a sua própria). Tudo indica que Fernando Henrique Cardoso premiou os estados nos quais foi o vitorioso na última eleição.

Com relação às variáveis que explicariam a estratégia dos presidentes com relação ao parlamento, a representação per capita nas duas Casas legislativas tem um efeito sobre a redistribuição. No Modelo 1, cada desvio padrão a mais na representação per capita - de São Paulo a Tocantins - representa um acréscimo de $\mathrm{R} \$ 265$ per capita no total das transferências de cada estado. Esses resultados não são puxados exclusivamente pelos estados menores - o coeficiente é praticamente o mesmo se retiramos Roraima, Amapá e Acre - e a relação é razoavelmente linear. Observe-se, entretanto, que o efeito da sobre-representação é mais de três vezes maior para as transferências não constitucionais (Modelo 3). Assim, o efeito da sobre-representação não é meramente um artefato das regras que regem as transferências constitucionais. Ele parece emergir do poder de barganha dos estados menores.

O coeficiente seguinte - percentual de cadeiras na coalizão de governo - indica, além disso, que as barganhas não são aleatórias, negociadas caso a caso. De todas as variáveis independentes testadas, o pertencimento à coalizão de governo do presidente apresenta os mais elevados índices de correlação. Os estados com maior representação na coalizão de sustentação legislativa do presidente recebem maiores montantes de transferências per capita. Cada desvio padrão a mais na representação do estado na coalizão do presidente (por exemplo, Rio Grande do Norte passando de sete para oito cadeiras na Câmara dos Deputados e de dois para três senadores na coalizão de governo de- 
pois de 1994) está associado a um ganho de $\mathrm{R} \$ 10$ per capita no total das transferências de cada estado. Se o presidente troca transferências por votos legislativos, ele parece fazê-lo mais freqüentemente com os deputados e senadores de sua própria coalizão. Testes adicionais revelaram-nos que o efeito de pertencimento à coalizão sobre as transferências não constitucionais per capita cresce com a sobre-representação para toda a amostra, embora com decrescente precisão para os estados maiores. Em outras palavras, os benefícios de pertencer à coalizão de sustentação legislativa do presidente são maiores para os estados menores, sobre-representados.

O coeficiente seguinte - pertencimento do governador à coalizão de governo - não é significativo em nenhuma estimativa. Mesmo o pertencimento do governador ao partido do presidente não obteve nenhuma correlação significativa. Esta constatação não é suficiente para rejeitar a visão de que os governadores agem como intermediários entre o parlamento e o presidente ou de que têm um papel importante nas relações federativas, mas todas as variáveis mantidas iguais, os estados controlados por governadores que fazem parte do partido ou da coalizão de governo do presidente não recebem mais transferências per capita do que aqueles controlados pelos partidos de oposição.

Passemos às variáveis de controle. Enquanto os anos eleitorais não têm qualquer impacto sobre as transferências constitucionais, os Modelos 3 e 4 revelam que as transferências não constitucionais são bem mais elevadas nestes anos. O Modelo 4 indica que a média destas transferências salta para $\mathrm{R} \$ 100$ per capita em anos eleitorais ${ }^{14}$.

Examinemos agora a veracidade dos freqüentes argumentos acerca do caráter redistributivo das transferências intergovernamentais. Neste caso, o PIB per capita estadual é a variável de controle mais importante. Observe-se que esta nem sequer se aproxima de algum nível de significância em nenhum dos modelos apresentados na Tabela 1.O total das transferências (constitucionais + não constitucionais) não favorece os estados mais pobres, e o coeficiente para as transferências não constitucionais é, na verdade, positivo, isto é, quanto mais pobre o estado, menos ele recebe.

Testes adicionais revelaram-nos que, no longo prazo, crescentes níveis de riqueza estão associados a maior volume de transferências. 
Um por cento de acréscimo no PIB per capita está associado a 0,65\% de acréscimo no total de transferências per capita e mais de $2 \%$ de acréscimo nas transferências não constitucionais. Entretanto, o coeficiente é negativo com relação às transferências constitucionais. Em suma, estas de fato se destinam aos estados mais pobres; mas a distribuição de transferências discricionárias não se pauta por critérios de necessidade.

\section{Transferências voluntárias}

A Tabela 2 apresenta os resultados para as transferências voluntárias no período 1996-2000 - excluindo o Distrito Federal - e confirmam com maior precisão os resultados encontrados com relação às transferências totais e não constitucionais para o período 1991-2000. Nossa variável dependente aqui se refere a desembolsos efetivamente executados de recursos com maior possibilidade de uso discricionário, em um período que cobre parte dos dois mandatos do presidente Fernando Henrique.

Tabela 2

Determinantes das Transferências Voluntárias Per Capita

1996-2000

\begin{tabular}{|c|c|c|}
\hline Votos para presidente na última eleição & 0,194 & $(0,048)^{* * *}$ \\
\hline Taxa de participação efetiva & $-0,146$ & $(0,862)$ \\
\hline Cadeiras por milhão de habitantes (média duas Casas) & 0,063 & $(0,007)^{* * *}$ \\
\hline Cadeiras na coalizão/total de cadeiras leg.(média duas Casas) & 6,285 & $(3,182)^{* *}$ \\
\hline Governo na coalizão do presidente & 0,035 & $(0,043)$ \\
\hline Log PIB per capita & $-0,254$ & $(0,115)^{* *}$ \\
\hline Ano eleição presidencial & 0,659 & $(0,282)^{* *}$ \\
\hline População (milhões) & $-0,095$ & $(0,022)^{* * *}$ \\
\hline Constante & 5,508 & $(0,472)^{* * *}$ \\
\hline $\mathrm{R}^{2}$ & \multicolumn{2}{|c|}{0,81} \\
\hline Número de estados & \multicolumn{2}{|c|}{26} \\
\hline Número de anos & \multicolumn{2}{|c|}{4} \\
\hline
\end{tabular}

Obs.: Efeitos fixos não incluídos.

Distrito Federal excluído.

${ }^{*}$ significativo a $10 \% ;{ }^{* *}$ significativo a $5 \% ;{ }^{* *}$ significativo a $1 \%$. 
Em primeiro lugar, a média das transferências voluntárias aumentou no ano eleitoral de 1998. O coeficiente para "ano de eleição presidencial" é altamente significativo, positivo e elevado $(0,659)$, o que indica que essas transferências voluntárias são de fato empregadas como um recurso de estratégia eleitoral.

A constatação de que o presidente premiou com as transferências voluntárias os estados que lhe deram maior apoio nas eleições de 1994 e de 1998 é confirmada. Cada desvio padrão a mais em "votos para o presidente na última eleição" está associado a um ganho de R 19 per capita em transferências voluntárias.

Passemos às estratégias parlamentares. O poder de barganha dos estados menores é confirmado com relação às transferências voluntárias. Mas os estados efetivamente favorecidos com transferências voluntárias foram aqueles cuja representação parlamentar era estratégica na coalizão de governo do presidente. Os mais elevados índices de correlação de nosso estudo referem-se a esta variável independente. Pertencer à coalizão de governo do presidente aumenta exponencialmente as chances dos parlamentares obterem recursos para seus estados ou municípios de origem. Os governadores que pertenciam à coalizão do presidente, entretanto, não foram beneficiados com transferências voluntárias. Essa variável nem sequer se aproxima de alguma correlação significativa.

\section{Empréstimos do FGTS}

A Tabela 3 apresenta os resultados com relação aos desembolsos do FGTS. Este tipo de desembolso não está sujeito ao mesmo grau de discricionariedade das transferências voluntárias, pois existe uma regulamentação para a definição dos orçamentos estaduais, isto é, o montante global de recursos que cada estado pode alocar em cada ano. Uma vez estimada a arrecadação líquida anual do Fundo, é calculado o montante de recursos de que disporá cada estado com base em critérios de distribuição diretamente proporcionais à população urbana e às carências habitacionais e de saneamento e inversamente proporcionais à capacidade de arrecadação do FGTS. Adicionalmente, a partir de 1995, a alocação dos recursos no interior dos estados passou a ser feita por comissões estaduais fortemente controladas pelos governadores (Arretche, 2000). 
Tabela 3

Determinantes dos Desembolsos do FGTS Per Capita

1997-2000

\begin{tabular}{l|cc}
\hline Votos para presidente na última eleição & $-0,074$ & $(0,11)$ \\
Taxa de participação efetiva & 7,768 & $(2,39)^{* * *}$ \\
Cadeiras por milhão de habitantes (média duas Casas) & $-0,076$ & $(0,02)^{* * *}$ \\
Cadeiras na coalizão/total de cadeiras leg. (média duas Casas) & 21,295 & $(2,59)$ \\
Gov. na coalizão do presidente & $-0,103$ & $(0,24)$ \\
Log PIB per capita & $-0,571$ & $(0,42)$ \\
Ano eleição presidencial & 0,039 & $(0,56)$ \\
População (milhões) & 0,033 & $(0,05)$ \\
Constante & 1,623 & $(2,03)$ \\
R & \multicolumn{2}{|c}{0,19} \\
Número de estados & \multicolumn{2}{|c}{26} \\
Número de anos & \multicolumn{2}{|c}{4} \\
\hline
\end{tabular}

Obs.: Efeitos fixos não incluídos.

Distrito Federal excluído.

*significativo a $10 \%$; ${ }^{* *}$ significativo a $5 \%$; ** significativo a $1 \%$.

Observe-se, assim, que essas regras favorecem os governadores dentro de seus respectivos estados, mas limitam o grau de discricionariedade na distribuição de recursos entre eles, favorecendo os mais pobres e mais populosos. A nosso juízo, são estas regras que limitaram o uso desse tipo para fins eleitorais, explicando que a variável "votos para presidente na última eleição" nem sequer se aproxime de algum grau de significância.

Similarmente, são essas regras que explicam a elevada correlação da variável "taxa de participação efetiva" bem como a correlação negativa da variável "cadeiras por milhão de habitantes". Em outras palavras, as regras para definição dos orçamentos estaduais do FGTS favorecem os estados maiores e penalizam os estados menores. Quanto mais populoso o estado, mais recursos do FGTS este tende a receber. Neste sentido, tais regras tendem a limitar o uso desses recursos como uma estratégia de obtenção de apoio eleitoral e/ou parlamentar.

Entretanto, é muito interessante como confirmação dos resultados encontrados com relação aos demais tipos de transferências que a variável "percentual de cadeiras do estado na coalizão de sustentação do presidente" seja mais uma vez a variável independente que apresente os mais elevados índices de correlação. Lembremos que a distri- 
buição de recursos entre os estados é limitada pelas regras. Isto significa que, uma vez alocados os empréstimos no interior dos estados, a etapa seguinte do jogo consiste na efetiva liberação dos projetos aprovados. Assim, para os parlamentares, pertencer à coalizão do presidente aumenta exponencialmente as chances de que o compromisso de liberação de recursos se torne crível.

Mais uma vez, confirma-se a constatação de que essa é uma relação entre a representação parlamentar dos estados e o Executivo federal. $\mathrm{O}$ "pertencimento do governador à coalizão" não se aproxima de qualquer nível de significância, sendo o índice na verdade negativo. Os governadores da oposição tinham, na verdade, mais chances de obter a efetiva liberação desses recursos.

\section{CONCLUSÕES}

Esse trabalho pretendeu caracterizar e avaliar os resultados de estratégias eleitorais e legislativas sobre a distribuição espacial de recursos, em uma federação com presidente forte, sobre-representação parlamentar nas duas Câmaras e parlamentares que têm incentivos para obter recursos para suas bases eleitorais. Os presidentes brasileiros contam com considerável poder sobre a execução de recursos de transferências e usam estes recursos para superar o desafio de preservar sua coalizão de sustentação parlamentar. Para tanto, canalizam os recursos de que dispõem para os estados que contam com maior número de parlamentares na coalizão. Os parlamentes, por sua vez, têm fortes incentivos para integrar a coalizão de governo, pois daí deriva a credibilidade de que seus estados e municípios de origem receberão recursos adicionais. Essa estratégia revela que os acordos entre os presidentes e o parlamento tendem a ser de longo prazo, e não aleatórios, em torno de cada votação legislativa. A noção de que os parlamentares e o Executivo federal estão envolvidos em generalizada negociação por recursos, na qual este último tem que construir uma maioria parlamentar para cada questão legislativa, revelou-se claramente equivocada. Além disso, não encontramos evidências de que o presidente favorece os governadores que pertencem ao seu partido ou à sua coalizão. Consistentemente com outros trabalhos recentes ${ }^{15}$, nossos resultados sugerem que o presidente usa seus recursos para manter uma coalizão legislativa claramente identificada.

(Recebido para publicação em maio de 2004)

(Versão definitiva em setembro de 2004) 


\section{NOTAS}

1. O número de membros da Comissão Mista do Orçamento cresceu ao longo do tempo. Em 1988, eram 60 (Pereira e Mueller, 2002). Em 1999, eram 84 (Souza, 2003).

2. Em 1995, a Resolução no $2 / 95$ estabeleceu um teto tanto para o número de emendas individuais - 20 - quanto para seu valor - $\mathrm{R} \$ 2$ milhões. Com relação às emendas coletivas, são permitidas até 5 para as comissões, 5 para as bancadas regionais e 10 para as bancadas estaduais.

3. O elevado grau de autonomia dos presidentes brasileiros com relação a "se" e "quando" as emendas parlamentares serão executadas pode, contudo, permitir-lhes assumir compromissos simultâneos.

4. Ames (2001) afirma que esta delegação de autoridade pode engendrar problemas. Os ministros podem ter as suas próprias agendas que não são necessariamente compatíveis com a do presidente. É importante, contudo, observar que o presidente não abdica de sua autoridade em favor dos ministros; a delegação pode ser retirada caso estes últimos não desempenhem adequadamente sua tarefa.

5. É possível que estes incentivos expliquem as taxas de migração partidária apresentadas por Melo (2000).

6. É importante, contudo, observar que mesmo as fórmulas empregadas para a distribuição das transferências automáticas são elas mesmas o resultado de barganhas políticas.

7. Dados obtidos junto à Caixa Econômica Federal.

8. Dados obtidos do site do Banco Federativo do Banco Nacional de Desenvolvimento Econômico e Social - BNDES. As transferências voluntárias são aquelas sobre as quais não há critérios constitucionais ou legais de partilha. Estas vêm crescendo em termos absolutos e relativos. Em 1995, envolveram R 5 bilhões, representando $18 \%$ do total das transferências constitucionais. Em 2000, foram R $\$ 13,5$ bilhões, representando 36\% das transferências constitucionais. Entretanto, parte significativa deste crescimento está associada aos desembolsos com o Sistema Único de Saúde-SUS, cujos critérios de partilha evoluíram de modo a que não mais fossem classificados como transferências voluntárias. Excluídas as transferências vinculadas ao SUS, as transferências voluntárias representaram R $\$ 4$ bilhões e $10 \%$ das transferências constitucionais em 2000 (Prado, 2001:36).

9. Dados obtidos da publicação oficial do Ministério da Fazenda. Os dados publicados pelo Ministério da Fazenda distinguem entre transferências constitucionais e "outras transferências", bem como transferências de capital. É possível separar as transferências constitucionais, as não constitucionais (para custeio e investimento) e o total das transferências (constitucionais + discricionárias para custeio + discricionárias para investimento).

10. Como os dados de transferência são desviados para a direita, utilizamos uma transformação com logaritmo natural.

11. Esta proxy não é suficientemente adequada para testar as teorias apresentadas. Seria preferível usar informações de survey para medir disposições ideológicas dos estados e calcular a intensidade das disputas, mas não dispomos desta informação. 
12. Os dados incluem observações para todos as 27 UFs. Testes de especificação de Hausman sugerem que o estimador de aleatoriedade é inapropriado. De qualquer modo, estamos cientes de que há importantes fatores não-mensurados que variam entre os estados; assim, todas as regressões mencionadas abaixo incluem efeitos fixos dos estados. Além disso, estamos preocupados com variações anuais e possíveis tendências; como uma matriz de dummys anuais é conjuntamente significativa em cada modelo, estas também foram incluídas. Desvios padrões corrigidos são calculados para lidar com a heteroscadasticidade de grupo. Para lidar com a correlação na série, modelos dinâmicos incluindo a defasagem à variável dependente estão registrados. A inclusão de uma variável dependente defasada, especialmente na presença de efeitos fixos, pode introduzir bias. Assim, especificações estáticas alternativas também foram exploradas usando a transformação de Prais-Winsten, as quais levaram a resultados similares.

13. Relação similar pode ser estabelecida pela simples interação entre margem de vitória e tamanho da população.

14. O teste para anos das eleições municipais também apresentou resultados significativos para as transferências não constitucionais.

15. Bevilaqua (1999) encontrou resultados similares para as negociações das dívidas estaduais no Brasil. Cheibub, Figueiredo e Limongi (2002) constataram que estados com mais forte representação na coalizão legislativa do presidente recebem maiores volumes per capita de investimento no Orçamento. Gibson e Calvo (2000) chegaram a conclusões similares para a Argentina, assim como Rao e Singh (2000) para a Índia. 


\section{REFERÊNCIAS BIBLIOGRÁFICAS}

ABRUCIO, Fernando Luiz. (1998), Os Barões da Federação. São Paulo, USP/Hucitec.

AFFONSO, R. B. A. (1995), “A Federação no Brasil: Impasses e Perspectivas”, in R. B. A. Affonso e P. L. B. Silva, A Federação em Perspectiva. São Paulo, FundAP.

ALMEIDA, M. H. T. (2001), “Federalismo, Democracia e Governo no Brasil: Idéias, Hipóteses e Evidências". BIB, nº 51, pp. 13-34.

AMES, Barry. (1995), “Electoral Rules, Constituency Pressures, and Pork Barrel: Bases of Voting in the Brazilian Congress". The Journal of Politics, vol. 57, pp. 324-343.

. (2001), The Deadlock of Democracy in Brazil. Ann Arbor, University of Michigan Press.

ARRETCHE, Marta. (2000), Estado Federativo e Politicas Sociais: Determinantes da Descentralização. Rio de Janeiro, Revan.

_. (2002), “Federalismo e Relações Intergovernamentais no Brasil: A Reforma dos Programas Sociais". Dados, vol. 45, nº 3, pp. 431-457.

BECKER, Gary. (1974), “A Theory of Social Interactions." Journal of Political Economy, vol. $82, \mathrm{n}^{-}$6, pp. 1.063-1.093.

BEVILAQUA, A. (1999), State-governments Bailouts in Brazil. Manuscrito.

CAMARGO, A. (1993), “La Federación Sometida. Nacionalismo Desarrollista e Inestabilidade Democrática", in M. Carmagnani (coord.), Federalismos Latinoamericanos: México/Brasil/Argentina. México, Fondo de Cultura Económica.

CAREY, John e REINHARDT, Gina. (2003), State-Level Ties and Legislative Coalitions in Brazil. Harvard University. Manuscrito.

CHEIBUB, José Antonio, FIGUEIREDO, Argelina e LIMONGI, Fernando. (2002), Presidential Agenda Power and Decision-Making in Presidential Regimes: Governors and Political Parties in the Brazilian Congress. Trabalho apresentado no Encontro Anual da American Political Science Association - APSA, Boston, MA, 29 de agosto.

COATE, Stephen. (1995), “Altruism, the Samaritan's Dilemma, and Government Transfer Policy". American Economic Review, vol. 85, nº 1, pp. 46-57.

COX, Gary e McCUBBINS, Matthew. (1986), "Electoral Politics as a Redistributive Game". Journal of Politics, vol. 48, pp. 370-389.

DILLINGER, William e WEBB, Steven. (1999), “Fiscal Management in Federal Democracies: Argentina and Brazil". Policy Research Working Paper, nํ2ㄹ, Washington, D.C., World Bank.

DIXIT, Avinash e LONDREGAN, John. (1996), “The Determinant of Success of Special Interests in Redistributive Politics". Journal of Politics, vol. 58, nํ4, pp. 1.132-1.155.

FIGUEIREDO, Argelina e LIMONGI, Fernando. (1999), Executivo e Legislativo na Nova Ordem Constitucional. Rio de Janeiro, Fundação Getulio Vargas Editora.

. (2002), “Incentivos Eleitorais, Partidos e Política Orçamentária”. Dados, vol. 45, nº

2, pp. 303-344. 
GIBSON, Edward e CALVO, Ernesto. (2000), "Federalism and Low-Maintenance Constituencies: Territorial Dimensions of Economic Reform in Argentina". Studies in Comparative International Development, vol. 35, nº 3, pp. 32-55.

KINZO, Maria D’Alva Gil. (1993), Radiografia do Quadro Partidário Brasileiro. São Paulo, Fundação Konrad Adenauer.

LASSWELL, Harold. (1936), Politics: Who Gets What, When and How? New York, P. Smith.

LINDBECK, Assar e WEIBULL, Jörgen. (1987), “Balanced-Budget Redistribution as the Outcome of Political Competition". Public Choice, no 52, pp. 273-297.

LOPES, Juares B. (1996), “Obstacles to Economic Reform in Brazil”, in A. Lijphart e C. Waisman (eds.), Institutional Design in New Democracies: Eastern Europe and Latin America. Boulder, CO, Westview.

MAINWARING, Scott. (1997), "Multipartism, Robust Federalism, and Presidentialism in Brazil", in S. Mainwaring e M. Shugart (eds.), Presidentialism and Democracy in Latin America. Cambridge, Cambridge University Press.

MELO, Carlos Ranulfo Félix de. (2000), “Partidos e Migração na Câmara dos Deputados". Dados, vol. 43, no 2, pp. 207-240.

MELO, Marcus André. (2002), Reformas Constitucionais no Brasil. Rio de Janeiro, Revan.

MELTZER, Allan e RICHARD, Scott. (1981), “A Rational Theory of the Size of Government". Journal of Political Economy, vol. 89, no 5, pp. 914-927.

MUSGRAVE, Richard. (1959), The Theory of Public Finance: A Study in Public Economy. New York, McGraw-Hill.

NICOLAU, Jairo Marconi. (1996), “Distribuição de Votos e Fragmentação Parlamentar", in Multipartidarismo e Democracia: Um Estudo sobre o Sistema Partidário Brasileiro (1985-94). Rio de Janeiro, Fundação Getulio Vargas Editora.

OATES, Wallace. (1972), Fiscal Federalism. New York, Harcourut Brace Jovanovich.

PALERMO, Vicente. (2000), “Como se Governa o Brasil? O Debate sobre Instituições Políticas e Gestão de Governo". Dados, vol. 43, nº 3, pp. 521-557.

PEREIRA, Carlos e MUELLER, Bernardo. (2002), Strategic Behavior in a Coalition-Based Presidential System: Executive-Legislative Relations in Budgetary Process in Brazil. Trabalho apresentado no Encontro Anual da American Political Science Association - APSA, Boston, MA, 29 de agosto.

PRADO, Sergio. (2001), Transferências Fiscais e Financiamento Municipal no Brasil. Relatório de Pesquisa Descentralização Fiscal e Cooperação Financeira Intergovernamental. EBAP/Fundação Konrad Adenauer.

RAO, M. Govinda e SINGH, Nirvikar. (2000), The Political Economy of Center-State Fiscal Transfers in India. University of California, Santa Cruz. Manuscrito.

SAMUELS, David. (2000), “Concurrent Elections, Discordant Results. Presidentialism, Singh Federalism, and Governance in Brazil". Comparative Politics, vol. 33, no 1, pp. $1-20$. 
SOUZA, C. (2003), "Federalismo e Conflitos Distributivos: Disputa dos Estados por Recursos Orçamentários Federais". Dados, vol. 46, nº 2, pp. 345-384.

STRÖMBERG, David. (2001), Radio's Impact on New Deal Spending. Institute for International Economic Studies, Stockholm. Manuscrito.

WEINGAST, Barry e MARSHALL, William. (1988), "The Industrial Organization of Congress, or, Why Legislatures, Like Firms, are not Organized as Markets". Journal of Political Economy, vol. 96, pp. 132-163. 


\author{
ABSTRACT \\ Distributive Policy in the Federation: Electoral Strategies, Legislative \\ Bargaining and Government Coalitions
}

This article discusses and tests different hypotheses about electoral and legislative strategies in Brazil, which is a federation with a strong president, over-representation in both chambers, and members of the legislative branch who are encouraged to seek funds for their constituencies. It examines the geographical distribution of budget and extra-budgetary funds during the period from 1990-2000 and measures the relative importance of captive and undecided districts, over-represented states, state governments, congressional party coalitions and indicators of poverty. It concludes that Brazilian presidents have considerable power over the transfer of resources and use it to preserve their political base in congress. They channel the resources available to them to the states with the largest number of legislators in the governing coalition.

Key words: distributive policy; electoral strategies; legislative bargaining

\title{
RÉSUMÉ
}

Politique de Répartition Budgétaire dans la Fédération Brésilienne: Stratégies Électorales, Marchandages Législatifs et Coalitions de Gouvernement

Dans ce travail, on discute et vérifie des hypothèses alternatives sur des stratégies électorales et législatives au Brésil - une fédération à président fort, avec une sur-représentation parlementaire dans ses deux Chambres et des parlementaires qui peuvent disposer de ressources au profit de leurs bases électorales. On y examine la répartition géographique des ressources budgétaires et extra-budgétaires pendant la période 1990-2000 et on mesure l'importance relative des zones électorales sûres et de celles des indécis, des états sur-représentés, des gouverneurs des états, des coalitions d'appui parlementaire et des indicateurs de pauvreté. En conclusion, on voit que les présidents brésiliens disposent d'un pouvoir considérable sur les ressources à transférer et s'en servent pour répondre au défi de préserver leurs bases de coalition au parlement: ils acheminent de préférence ces ressources vers les états où le nombre de parlementaires favorables au gouvernement est le plus élevé.

Mots-clé: politique de répartition budgétaire; stratégies électorales; marchandages législatifs 